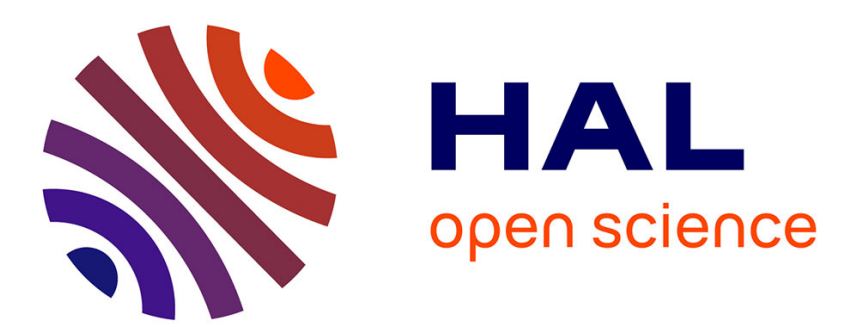

\title{
Theoretical and numerical study of strain localization under high strain rate solicitation
}

Nicolas Ranc, Renaud Raynal, Laurent Taravella, Vincent Pina, Pasqua Herve

\section{To cite this version:}

Nicolas Ranc, Renaud Raynal, Laurent Taravella, Vincent Pina, Pasqua Herve. Theoretical and numerical study of strain localization under high strain rate solicitation. Journal de Physique, 2006, 134, pp.325-330. 10.1051/jp4:2006134050 . hal-00283565

\section{HAL Id: hal-00283565 \\ https://hal.science/hal-00283565}

Submitted on 27 Mar 2018

HAL is a multi-disciplinary open access archive for the deposit and dissemination of scientific research documents, whether they are published or not. The documents may come from teaching and research institutions in France or abroad, or from public or private research centers.
L'archive ouverte pluridisciplinaire HAL, est destinée au dépôt et à la diffusion de documents scientifiques de niveau recherche, publiés ou non, émanant des établissements d'enseignement et de recherche français ou étrangers, des laboratoires publics ou privés. 


\title{
Theoretical and numerical study of strain localization under high strain rate solicitation
}

\author{
N. Ranc ${ }^{1}$, R. Raynal ${ }^{1}$, L. Taravella ${ }^{2}$, V. Pina ${ }^{1}$ and P. Hervé ${ }^{1}$ \\ ${ }^{1}$ LEEE, E.A. 387 - Université Paris X, 1 chemin Desvallières, 92410 Ville d'Avray, France \\ ${ }^{2}$ CEP DGAIDET, 16 bis, Avenue Prieur de la Côte d'Or, 94114 Arcueil cedex, France
}

\begin{abstract}
Our study deals with the dynamic behavior of metallic materials and in particular of titanium alloy TA6V. For high strain rates, we can notice the occurrence of a phenomenon called adiabatic shearing. This phenomenon is about a plastic instability, which results in the appearance of a strain localization in narrow bands. In this paper we developed a thermo mechanical model to reproduce the formation and the propagation of adiabatic shear bands. A Johnson Cook thermo visco plastic behavior law was chosen for the titanium alloy TA6V. The law parameters were identified from static and dynamic torsion tests at various temperatures between ambient and $350^{\circ} \mathrm{C}$. A $2 \mathrm{D}$ numerical simulation of torsion test was performed with the explicit finite elements code Abaqus. The thermo mechanical coupling and the heat conduction are taken into account. A roughness defect was inserted in the centre of a torsion specimen. The results showed that the strain of localization and the shear band speed increase when the amplitude and the size of the defect decrease.
\end{abstract}

\section{INTRODUCTION}

Adiabatic shearing is a fracture mechanism generally observed in ductile materials during dynamical solicitations. This phenomenon is characterized by a localization of the plastic deformation in narrow bands [1]. Depending on materials, the width of these bands can vary between ten and a few hundreds micrometers. The mechanisms concerned in the formation of these bands are also partly known, but their modelling remains a complex problem [2].

In this paper we propose a two dimensional thermo mechanical model in order to simulate the initiation and the propagation of ASB. In a first part we argue the choice of a Johnson Cook behavior law for the titanium alloy TA6V and we present the identification of the law parameters from static and dynamic tests at various temperatures. In a second part, we present the thermo mechanical model, the resolution techniques with the finite elements method and the calculation results.

\section{DETERMINATION OF THE BEHAVIOR LAW OF TITANIUM ALLOY TA6V}

\subsection{Mechanical tests}

A series of torsion tests were carried out on thin wall tubular specimen at different strain rates and temperatures. The internal diameter of the specimen, the thickness of the thin wall and the length of the tubular part are respectively of $9 \mathrm{~mm}, 0.4 \mathrm{~mm}$ and $5 \mathrm{~mm}$. Table 1 sums up the conditions of these different tests. The static and dynamic tests were performed with the torsion Kolsky (Split-Hopkinson) bars device. In the case of the static tests, the output bar is blocked and the input bar is subjected to a torque with a hydraulic jack. The nominal shear strain of the specimen and the shear stress are measured respectively by an optical extensometer and by strain gauges placed on the bars. The dynamic tests were performed at different temperatures between ambient and $300^{\circ} \mathrm{C}$. The specimen is heated with a furnace. 
Table 1. Dynamic and static tests.

\begin{tabular}{|l|c|c|c|c|c|c|c|c|c|c|}
\hline Test reference & S1 & S2 & S3 & D1 & D2 & D3 & D4 & T1 & T2 & T3 \\
\hline Shear strain rate in s & 0.097 & 0.104 & 0.101 & 776 & 571 & 565 & 406 & 365 & 222 & 301 \\
\hline Temperature in ${ }^{\circ} \mathrm{C}$ & 20 & 20 & 20 & 20 & 20 & 20 & 20 & 300 & 300 & 230 \\
\hline
\end{tabular}

\subsection{Choice of a behaviour law}

Figures 1 and 2 highlight the strain hardening, the strain rate hardening and the thermal softening of the titanium alloy TA6V. These experimental results allow us to choose a Johnson Cook elasto thermo visco plastic behavior law. The yield stress can then be expressed:

$$
\begin{gathered}
\sigma\left(\varepsilon_{e q}, \dot{\varepsilon}_{e q}\right)=\left(A+B \varepsilon_{e q}^{n}\right)\left(1+C \ln \left(\frac{\dot{\varepsilon}_{e q}}{\dot{\varepsilon}_{0}}\right)\right) \text { for } T<T_{t} \\
\sigma\left(\varepsilon_{e q}, \dot{\varepsilon}_{e q}, T\right)=\left(A+B \varepsilon_{e q}^{n}\right)\left(1+C \ln \left(\frac{\dot{\varepsilon}_{e q}}{\dot{\varepsilon}_{0}}\right)\right)\left(1-\left(\frac{T-T_{t}}{T_{f}-T_{t}}\right)^{m}\right) \text { for } T>T_{t}
\end{gathered}
$$

and in the case of a shear solicitation:

$$
\sigma\left(\varepsilon_{e q}, \dot{\varepsilon}_{e q}, T\right)=\left(A+B \varepsilon_{e q}^{n}\right)\left(1+C \ln \left(\frac{\dot{\varepsilon}_{e q}}{\dot{\varepsilon}_{0}}\right)\right)\left(1-\left(\frac{T-T_{t}}{T_{f}-T_{t}}\right)^{m}\right)
$$

\subsection{Identification of the behavior law parameters}

\subsubsection{Strain hardening parameters}

The strain hardening parameters $A^{\prime}, B^{\prime}$ et $n$ were identified from tests $\mathrm{S} 1, \mathrm{~S} 2$ and $\mathrm{S} 3$. We choose a reference strain rate $\left(\dot{\gamma}_{0}\right)$ of $0.1 \mathrm{~s}^{-1}$ and a transition temperature $\left(T_{t}\right)$ of $20^{\circ} \mathrm{C}$. A minimization technique allows to determine the parameters $A^{\prime}, B^{\prime}$ and $n$. We obtain $A^{\prime}=500 \mathrm{MPa}, B^{\prime}=160 \mathrm{MPa}$, and $n=0.25$. Figure 3 shows the experimental evolution of the shear stress with the plastic shear strain during test $\mathrm{S} 1$ and its modelling with the Johnson Cook law.

\subsubsection{Strain rate hardening parameters}

The strain rate hardening parameters $C^{\prime}$ is identified from the dynamic tests at ambient temperature (tests D1, D2, D3, D4). If we make the assumption that the test is isothermal and if we note $\tau_{10 \%}$ the

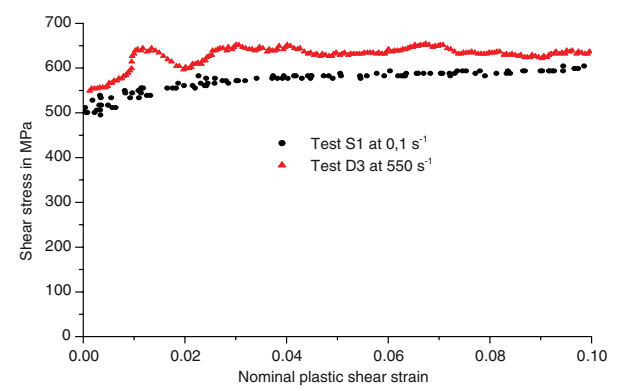

Figure 1. Strain hardening, strain rate hardening in titanium alloy TA6V.

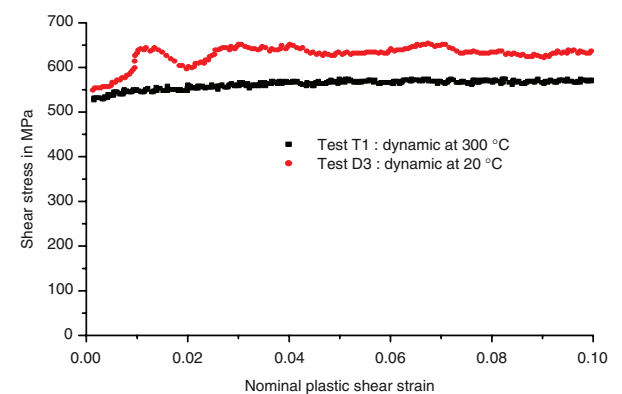

Figure 2. Thermal softening in titanium alloy TA6V. 


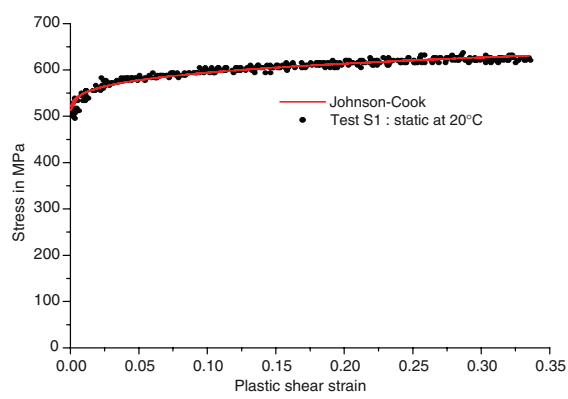

Figure 3. Identification of the strain hardening parameters.

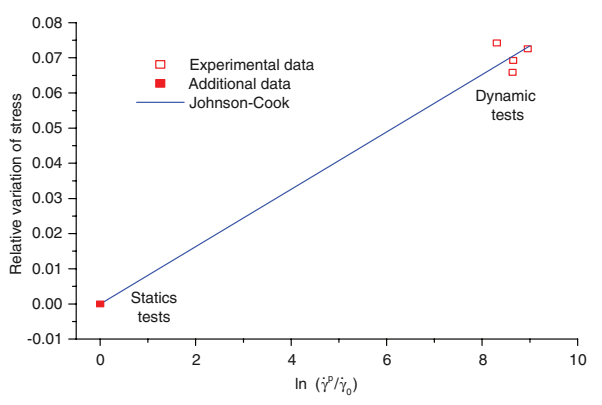

Figure 4. Identification of the strain rate hardening parameter.

yield shear stress for a plastic shear strain of $10 \%$ and at ambient temperature, we obtain:

$$
\frac{\tau-\tau_{10 \%}}{\tau_{10 \%}}=C^{\prime} \ln \left(\frac{\dot{\gamma}_{p}}{\dot{\gamma}_{0}}\right)
$$

The figure 4 shows the relative variation of shear stress according to the logarithm of the plastic shear strain rate for the for dynamic tests at ambient temperature. An additional data corresponding to the static tests was added. A linear regression enables to determine the value of $C^{\prime}$. We find $C^{\prime}=0.008$.

\subsubsection{Thermal softening parameter}

In order to determine the thermal softening parameter $m$, we use the dynamic tests at $230^{\circ} \mathrm{C}$ (test T1) and at $300^{\circ} \mathrm{C}$ (tests $\mathrm{T} 2$ and T3). The Johnson cook law allows to write the yield stress for a plastic shear strain of $10 \%$ according to the temperature and the strain rate:

$$
\tau=\tau_{10 \%} f_{d}\left(1-\left(\frac{T-T_{t}}{T_{f}-T_{t}}\right)^{m}\right) \quad \text { with } \quad f_{d}=\left(1+C^{\prime} \ln \left(\dot{\gamma}_{p} / \dot{\gamma}_{0}\right)\right)
$$

We obtain then the relative variation of shear stress:

$$
\frac{\tau_{10 \%} f_{d}-\tau}{\tau_{10 \%} f_{d}}=\left(\theta^{*}\right)^{m} \quad \text { with } \quad \theta^{*}=\frac{T-T_{t}}{T_{f}-T_{t}}
$$

Figure 5 shows the relative variation of shear stress according to the logarithm of $\theta^{*}$ for dynamic tests at different temperatures. An additional data corresponding to the melting point was added. A linear regression enables to quantify the parameter $m$. We find $m=1.055$.

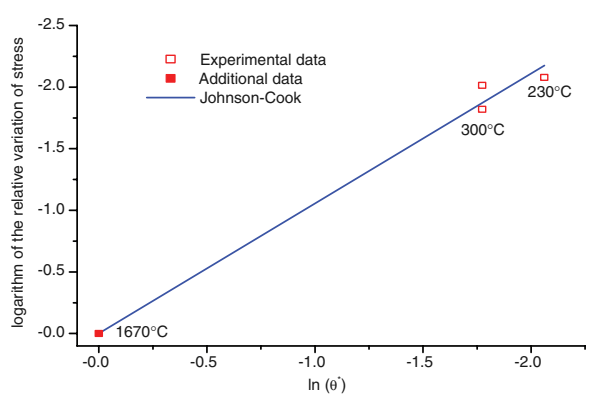

Figure 5. Identification of the thermal softening parameter. 
Table 2. Value of the Johnson cook behaviour law parameters.

\begin{tabular}{|l|c|c|c|c|c|c|c|c|}
\hline Parameter & $A(\mathrm{MPa})$ & $B(\mathrm{MPa})$ & $n$ & $C$ & $\dot{\varepsilon}_{0}\left(\mathrm{~s}^{-1}\right)$ & $T_{t}\left({ }^{\circ} \mathrm{C}\right)$ & $T_{f}\left({ }^{\circ} \mathrm{C}\right)$ & $m$ \\
\hline Value & 866 & 318 & 0.25 & 0.008 & $5.77 \times 10^{-2}$ & 20 & 1670 & 1.055 \\
\hline
\end{tabular}

\subsubsection{Conclusion}

The parameters of the Johnson Cook law in the case of the titanium alloy TA6V are summed up in table 2 in a general three-dimensional solicitation case.

\section{THERMO MECHANICAL MODEL}

\subsection{Geometry and mesh}

The simulation of the ASB formation is carried out in a thin wall tubular specimen with an internal diameter of $9 \mathrm{~mm}$, a wall thickness of $0.4 \mathrm{~mm}$ and a length of $2 \mathrm{~mm}$. As the thickness is very small compared with the diameter of the specimen, we suppose that the stress, the temperature and the deformation remain homogeneous in the thickness of the thin wall. This assumption enables us to use a two dimensional model. Therefore, the useful part of the specimen is modelled by a parallelepiped of length $28.3 \mathrm{~mm}$, width $2.0 \mathrm{~mm}$ and thickness $0.4 \mathrm{~mm}$. The mechanical boundary conditions are detailed on figure 6 . For the thermal problem the boundary conditions will be considered adiabatic. The initial temperature of the specimen is $20^{\circ} \mathrm{C}$.

We suppose that the ASB is initiated by only one roughness or metallurgical defect and will propagate starting from this critical defect. In the model, it will be taken into account by a small reduction of the specimen thickness on a circular zone located at the center of the specimen. The characteristics of the defect are model by two parameters: its amplitude defined by the relative variation of thickness on the circular zone and its diameter. In our calculations, the amplitude and the diameter will vary respectively between $1 \%$ and $5 \%$ and between $20 \mu \mathrm{m}$ and $100 \mu \mathrm{m}$.

In the case of localization phenomena, significant gradients of strain and temperature appear. Therefore, it is necessary to have a mesh which is sufficiently refined in the zones where the ASB will develop (figure 7). In our case, the size of the elements located at the center of the specimen useful part of the specimen is equal to $10 \mu \mathrm{m}$ and is thus lower than the width of the bands measured in experiments $(20 \mu \mathrm{m}$ for TA6V). A more refined mesh with an element size of $5 \mu \mathrm{m}$ showed than the results remain unchanged.

\subsection{Equations}

In order to take into account the effects of the temperature and the speed of the solicitation on the initiation of the band, we chose a fully coupled thermo mechanical model. The inertia effects and the

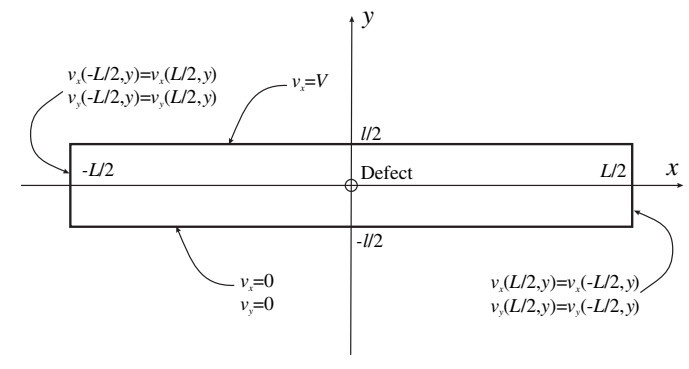

Figure 6. Mechanical boundary conditions.
Figure 7. Mesh of the specimen. 
heat conduction are also taken into account. The heat equation is written then:

$$
\rho C \frac{\mathrm{d} T}{\mathrm{~d} t}=\beta \sigma: \dot{\varepsilon}_{p}+\lambda \Delta T
$$

with $\rho=4400 \mathrm{~kg} \cdot \mathrm{m}^{-3}$ the density, $C=656 \mathrm{JK}^{-1} \mathrm{~kg}^{-1}$ the heat capacity, $\lambda=9 \mathrm{Wm}^{-1} \mathrm{~K}^{-1}$ the heat conductivity, and $\beta=0.9$ the Taylor Quinney coefficient for the TA6V.

The material behavior will be considered as elasto thermo visco plastic with a Johnson Cook plastic flow law presented and identified in the previous paragraph for the titanium alloy TA6V.

\subsection{Calculations}

The fully coupled thermo mechanical calculations were carried out with the finite elements code Abaqus Explicit. The selected elements are CPS3RT and CPS4RT types (plate elements in plane stress with temperature and with 3 or 4 nodes).

\subsection{Results}

Figure 8a shows the evolution of the shear stress according to the shear strain for a defect with a diameter of $40 \mu \mathrm{m}$ and an amplitude of $5 \%$.

We can notice a maximum of stress for a shear strain of $40 \%$ which corresponds to the onset of the plastic instability. For a plastic shear strain of $120 \%$, it appears a violent fall of the shear stress which characterizes the beginning of the band propagation. The figure $8 \mathrm{~b}$ represents the temperature field at various moments located on the stress-strain curve. As the temperature field is symmetric only a half of the specimen is represented. On the first temperature field, we can notice a low heterogeneity near the defect. The second field shows the initiation of ASB near the defect which is characterized by a strong heterogeneity of the temperature. The last two fields show the evolution of this band and highlight its propagation along the specimen from the right side to the left.

Figures 9 and 10 respectively show the evolution of the shear strain at the violent fall of the stress (localization strain) according to the size and the amplitude of the defect. The increase in these two parameters leads to a reduction in the localization strain. Figure 11 and 12 give the evolution of the average of the propagation velocity of the ASB between the defect and the quarter of the test-tube according to the size and the amplitude of the defect. An increase in these two parameters leads to a reduction in the band speed.

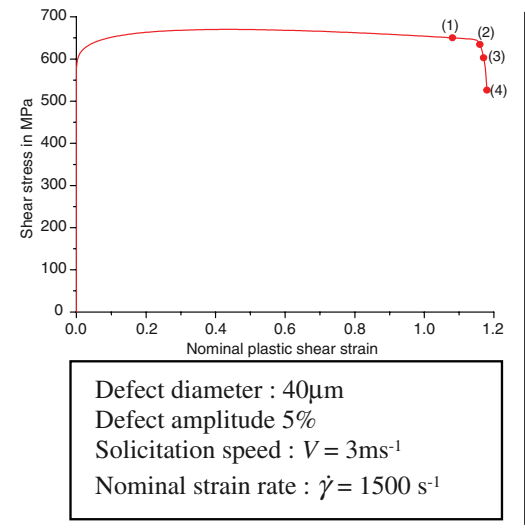

a)

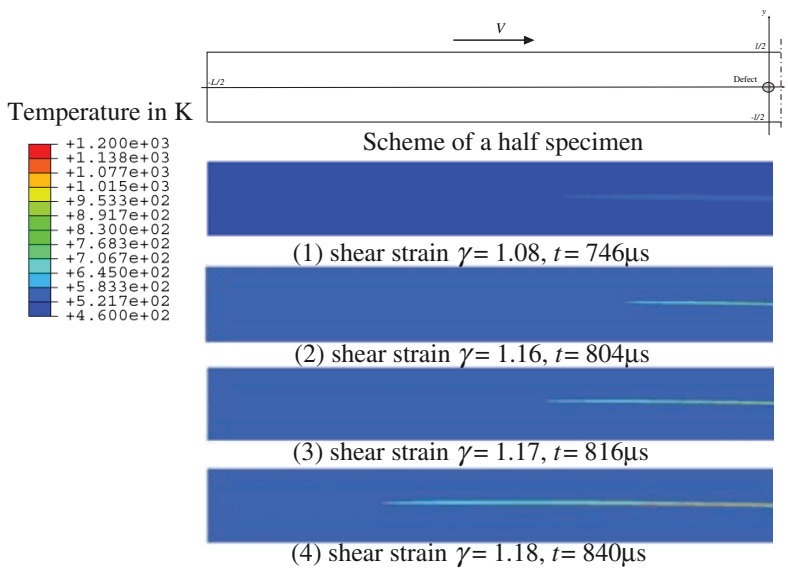

b)

Figure 8. Drop in the shear stress and propagation of ASB (solicitation speed: $V=3 \mathrm{~ms}^{-1}$ ). 


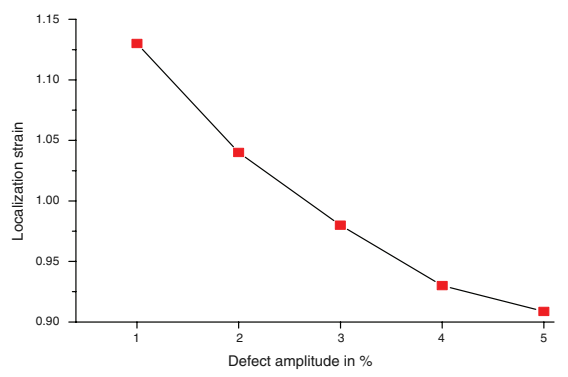

Figure 9. Effect of the defect amplitude on the localization strain for a defect diameter of $100 \mu \mathrm{m}$.

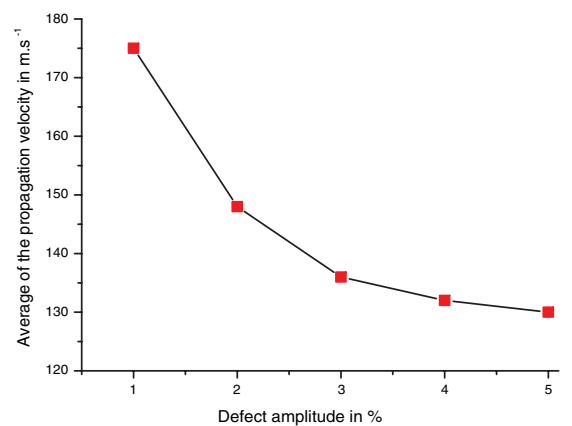

Figure 11. Effect of the defect amplitude on the band velocity for a defect diameter of $100 \mu \mathrm{m}$.

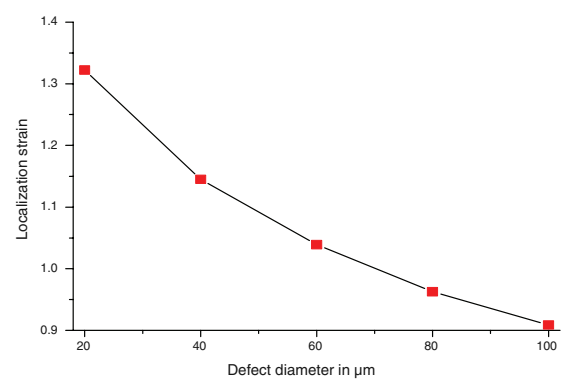

Figure 10. Effect of the defect diameter on the localization strain for a defect amplitude of $5 \%$.

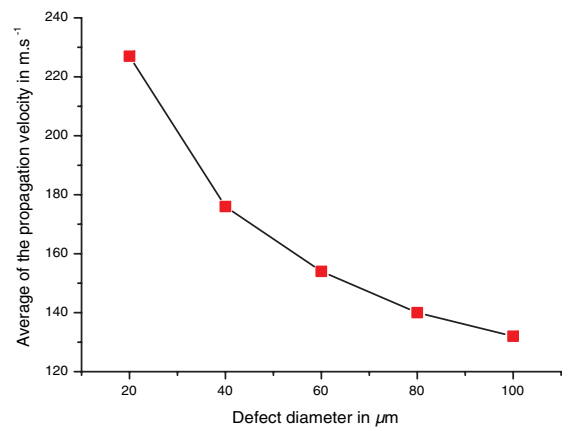

Figure 12. Effect of the defect diameter on the band velocity for a defect amplitude of $5 \%$.

\section{CONCLUSION}

The thermo mechanical model presented in this paper simulates the initiation and the propagation of an ASB starting from a defect. The results highlight the effect of the defect on the localization strain and the average of the band speed. The magnitude of the localization to localization seems however higher than those found in experiments in the literature $[4,5]$. A possible improvement of the model will consist in considering several defect and their mutual interactions.

\section{References}

[1] Y. Bai and B. Dodd, Adiabatic shear localization Occurrence, Theories and Applications (Pergamon Press, 1992).

[2] T. W. Wright, The physics and mathematics of adiabatic shear bands (Cambridge University Press, 2002).

[3] N. Ranc, "Etude des champs de température et de déformation dans les matériaux métalliques sollicités à grande vitesse de déformation”, Thesis, University of Paris X, France (2004).

[4] C. S. Liao and J. Duffy "Adiabatic shear bands in a TA6V titanium alloy", J. Mech. Phys. Solids 46 (1998) 2201-2231.

[5] N. Ranc, V. Pina, P. Herve, L. Taravella. and P. F. Louvigne, 2003, "Experimental study of temperature heterogeneity in metallic materials under high strain rate solicitation" Journal de physique IV France 110 (2003) 417-422. 